\title{
A Elitização da Linguagem como Obstáculo ao Acesso À Justiça
}

\author{
La Elitización del Lenguaje como Obstáculo al Acceso A La Justicia
}

The Elitization of Language as an Obstacle to Access To Justice

\author{
Fernanda Moreira Stocher ${ }^{1}$ \\ Maria Fernanda Corrêa Freitas ${ }^{2}$ \\ Deisemara Turatti Langoski ${ }^{3}$
}

\begin{abstract}
Resumo
A Constituição Federal de 1988, traz entre os Direitos e Garantias Fundamentais, nos Direitos Individuais e Coletivos, o acesso à justiça (artigo $5^{\circ}, \mathrm{XXXV}$ ). Este é um direito humano essencial da cidadania. Contudo, existem limitações para que o acesso à justiça seja um direito justo e legítimo nos aspectos sociais, culturais, educacionais e econômicos. O objetivo deste trabalho é analisar como a elitização da linguagem afeta a vida da sociedade brasileira. Utiliza-se o método de abordagem dedutivo e a técnica de pesquisa bibliográfica. Em pleno século XXI, muitos brasileiros desconhecem seus direitos e deveres, não alcançando a justiça social. Persiste a dificuldade de entendimento e compreensão das leis e do linguajar legal: é o fenômeno conhecido como elitização da linguagem, verbal ou não verbal, uma das principais explicações para a incompreensão do conhecimento jurídico, à justiça e ao judiciário. O "juridiquês" - uso desnecessário e excessivo do jargão jurídico e de termos técnicos, torna-se um obstáculo à informação e, por consequência, ocasiona ruídos na comunicação entre operadores do direito e cidadãos-usuários. Muitas vezes, para demonstrar conhecimento, juristas fazem uso de expressões técnicas e termos em latim desnecessários. Deste modo, ao invés de existir a aproximação entre o sistema judiciário, profissionais do direito e a sociedade, verifica-se o distanciamento e a não promoção do acesso à justiça, visto que é um recurso escasso e desigual no Brasil.
\end{abstract}

Palavras-chave: Acesso à justiça. Elitização da linguagem. Cidadania.

\section{Resumen}

La Constitución Federal de 1988, trae entre los Derechos y las Garantías Fundamentales, en los Derechos Individuales y Colectivos, el acceso a la justicia (artículo 5, XXXV). Este es un derecho humano esencial de la ciudadanía. Sin embargo, existen limitaciones para que el acceso a la justicia sea un derecho justo y legítimo en los aspectos sociales, culturales, educativos y económicos. El objetivo de este trabajo es analizar cómo la elitización del lenguaje afecta la vida de la sociedad brasileña. Se utiliza el método de abordaje deductivo y la técnica de investigación bibliográfica. En pleno siglo XXI, muchos brasileños desconocen sus derechos y deberes, no alcanzando la justicia social. Persiste la dificultad de entendimiento y comprensión de las leyes y del lenguaje legal: es el fenómeno conocido como elitización del lenguaje, verbal o no verbal, una de las principales explicaciones para la incomprensión del conocimiento jurídico, la justicia y al poder judicial. El "juridiquês" uso innecesario y excesivo de la jerga jurídica y de términos técnicos, se convierte en un obstáculo a la información y, por consiguiente, ocasiona ruidos en la comunicación entre operadores del derecho y ciudadanosusuarios. Muchas veces para demostrar conocimiento, los juristas hacen uso de expresiones técnicas y términos en latín innecesarios. De este modo, en vez de existir la aproximación entre el sistema judicial, profesionales del derecho y la sociedad, se verifica el distanciamiento y la no promoción del acceso a la justicia, ya que es un recurso escaso y desigual en Brasil.

\footnotetext{
${ }^{1}$ Acadêmica do Curso de Direito. Universidade Federal do Pampa - UNIPAMPA; Sant'ana do Livramento, Rio Grande do Sul, Brasil. fernandastocher@gmail.com.

${ }^{2}$ Acadêmica do Curso de Direito. Universidade Federal do Pampa - UNIPAMPA; Sant'ana do Livramento, Rio Grande do Sul, Brasil. marfenana2000@gmail.com.

${ }^{3}$ Doutora em Direito. Universidade Federal de Santa Catarina - UFSC. Sant'ana do Livramento, Rio Grande do Sul, Brasil. deisemaraturatti@unipampa.edu.br
} 
Palabras clave: Acceso a la justicia. Elitización del lenguaje. Ciudadanía.

\begin{abstract}
The Federal Constitution of 1988 brings between the Fundamental Rights and Guarantees, in the Individual and Collective Rights, access to justice (article 5, XXXV). This is an essential human right of citizenship. However, there are limitations to access to justice as a fair and legitimate right in social, cultural, educational and economic aspects. The objective of this work is to analyze how the elitism of language affects the life of Brazilian society. The method of deductive approach and the bibliographic research technique are used. In the 21st century, many Brazilians are unaware of their rights and duties, not achieving social justice. The difficulty of understanding the laws and legal language persists: it is the phenomenon known as the elitization of language, verbal or nonverbal, one of the main explanations for incomprehension of legal knowledge, justice and the judiciary. The "juridiquês" - unnecessary and excessive use of legal jargon and technical terms, becomes an obstacle to information and, as a consequence, causes noise in the communication between legal operators and citizen-users. Often to demonstrate knowledge, jurists make use of technical expressions and unnecessary Latin terms. In this way, instead of the approximation between the judicial system, law professionals and society, there is a lack of access to justice, as it is a scarce and unequal resource in Brazil.
\end{abstract}

Keywords: Access to justice. Elitization of language. Citizenship.

\title{
1. Introdução
}

Sabe-se que a linguagem, meio de expressão, é essencial para a plena comunicação e entendimento humano; especialmente a jurídica, pois permite que a sociedade possa compreender e estar ciente de seus direitos e deveres.

O acesso à justiça, princípio garantido pela Constituição Federal, é um direito humano, ou seja, de todos, independente de quaisquer distinções, fundamental para uma completa cidadania e para a melhor vivência em sociedade. Engloba não apenas a permissão de recorrer ao Estado para defender seus direitos, mas também, ter acesso e entender o ordenamento jurídico, o que, por vezes, se torna um obstáculo.

A linguagem jurídica foi formada ao longo da história, uma construção antiga e de diversas influências, repleta de termos técnicos e de difícil compreensão para os leigos, o que dificulta e compromete o acesso à justiça.

\section{A linguagem como meio de comunicação}

Segundo o Dicionário Houaiss da Língua Portuguesa, o termo linguagem origina-se de língua + agem, por influência do provençal (dialeto falado na antiga Provença) "lenguatge". No geral refere-se ao meio de comunicar ideias ou sentimentos através de signos convencionais, sonoros, gráficos ou gestuais. Podendo ainda ser sinônimo de língua enquanto sistema.

Segundo Wilhelm Stern (1907), existem três raízes da linguagem, são elas: a tendência expressiva, a tendência social e a tendência “intencional”. Esta última é a utilizada por nós, 
seres racionais. De acordo com o psicólogo, o homem adquire a capacidade de proferir algo através de palavras para significar coisas objetivas.

Pode-se dizer que a linguagem é a forma de expressar algo para alguém. E, segundo o psicólogo Lev Semenovich Vygotsky (1962), afirma em sua Teoria do Desenvolvimento Cognitivo que "uma palavra sem significado é um som vazio; portanto, o significado é um critério da palavra e um componente indispensável”. Logo, o principal objetivo da linguagem é realizar a função de meio de comunicação, onde podemos organizar a vida em sociedade através do diálogo e da racionalidade.

O desenvolvimento da linguagem implica na aquisição plena do sistema linguístico que nos possibilita a inserção no meio social, a possibilidade de assumir a nossa identidade, além do desenvolvimento de vários outros aspectos cognitivos necessários à formação e interação entre os seres humanos.

Há necessidade de ressaltar, nesse contexto, sobre as dificuldades encontradas pelos leitores quanto à acessibilidade do vocabulário, uma vez que uma linguagem restrita a poucos, deixa de lado muitas pessoas que estão acostumadas a um vocabulário limitado e simplificado, as quais não conseguem entender, nem mesmo interpretar.

Segundo estudos do Ibope Inteligência em 2018, no Brasil, 3 em cada dez brasileiros (jovens e adultos) possuem analfabetismo funcional, o que equivale a $29 \%$ da população total (aproximadamente 38 milhões). Contudo, os dados do Indicador do Alfabetismo Funcional (Inaf) 2018 afirma que há dez anos a taxa de brasileiros nesse contexto está estagnada. Analfabeto funcional é aquele que sabe ler e escrever, mas não possui capacidade de interpretar o que lê nem de usar a leitura e a escrita em atividades do cotidiano. Esse aspecto além de privar as pessoas da comunicação, dificulta o acesso a direitos e deveres de cidadania.

\section{Acesso à Justiça}

$\mathrm{O}$ princípio do Acesso à Justiça, encontrado no Art. 5, XXXV da Constituição Federal, diz que "a lei não excluirá da apreciação do Poder Judiciário lesão ou ameaça de direito" e também é conhecido como princípio da inafastabilidade do controle jurisdicional ou princípio do direito de ação.

Obter uma definição precisa e universal de "acesso à justiça" é uma tarefa realmente complexa. Na clássica obra Acesso à Justiça, Mauro Cappelletti e Bryant Garth, os autores afirmam que a expressão é "reconhecidamente de difícil definição". (CAPPELLETTI; GARTH. 1988, p.08).

O conceito de acesso à justiça sofreu constantes transformações, evoluiu e ainda permanece em meio às discussões pertinentes da atualidade. Engloba a questão do direito de 
ação, defesa e proteção do Estado, sendo ela justa e igual para todos, mas a realidade difere, pois trata-se apenas de uma igualdade formal.

Com a evolução dos direitos humanos e sua aceitação mundial, o acesso à justiça adquiriu seu lugar entre eles, sendo fundamental para a cidadania e plena vivência de um indivíduo e garantindo sua efetivação, como consta no Art. $8^{\circ}$, parágrafo $1^{\circ}$ da Convenção Interamericana sobre Direitos Humanos - São José da Costa Rica (1969).

Toda pessoa tem direito de ser ouvida, com as devidas garantias e dentro de um prazo razoável, por um juiz ou tribunal competente, independente e imparcial, estabelecido anteriormente por lei, na apuração de qualquer acusação penal contra ela, ou para que se determinem seus direitos ou obrigações de natureza civil, trabalhista, fiscal ou de qualquer natureza.

Outro aspecto abordado pelo termo "acesso à justiça" refere-se ao alcance da justiça, bem como da legislação, pela sociedade em geral, isto é, a compreensão e o entendimento da linguagem jurídica pela população.

A Justiça requer a acessibilidade, de forma equitativa para todas as pessoas, sendo assim, é necessário que todos possam compreender a linguagem jurídica, e desta forma, possam estar a par de seus direitos e deveres.

As barreiras ao acesso à justiça são inúmeras e encontram-se nos diversos âmbitos da sociedade, podem ser econômicas, sociais, culturais, históricas e até mesmo na própria área jurídica, como por exemplo, o desconhecimento da lei e dos processos, a desconfiança nos procedimentos, a morosidade do judiciário, entre tantos outros obstáculos.

Em 1891 houve a tripartição de Poderes no Brasil e, como consequência, toda a jurisdição sobre uma controvérsia jurídica é efetuada, única e exclusivamente, pelo Poder Judiciário. Com o fim da autotutela, todo o dever de resolver imparcialmente os conflitos recai para o Estado, como está positivado na Constituição Federal da República Federativa do Brasil através do princípio da inafastabilidade do controle jurisdicional. (Art. 5ª XXXV)

Segundo Alexandre de Moraes (1998, p. 197):

O Poder Judiciário, desde que haja plausibilidade de ameaça ao direito, é obrigado a efetivar o pedido de prestação judicial requerido pela parte de forma regular, pois a indeclinabilidade da prestação judicial é princípio básico que rege a jurisdição, uma vez que a toda violação de um direito responde uma ação correlativa, independentemente de lei especial que a outorgue.

Cabe à pessoa lesada o requerimento de prestação judicial, de forma regular. Todavia, para que isso aconteça é de fundamental importância que a Justiça seja acessível para a plena reparação dos direitos ameaçados. É necessária uma Justiça humanizadora, que perceba as 
limitações de cada indivíduo, demonstrando de forma clara os instrumentos utilizados para acessá-la, a fim de garantir a compreensão total dos seus deveres e direitos, caso contrário, será uma Justiça elitizada, para poucos.

\section{A elitização da linguagem como obstáculo à plena compreensão}

A linguagem jurídica foi formada ao longo dos tempos, com origem no latim, manteve suas heranças que ultrapassam gerações; uma construção sociocultural e histórica que, ainda hoje, persiste e tem seus efeitos, por vezes negativos, em situações cotidianas em que a sociedade não consegue ter um acesso pleno, e que é seu por direito, à justiça.

Para quem estuda a língua e as terminologias, o termo "juridiquês" é a linguagem técnica, ou seja, a língua peculiar dos operadores do Direito e que utiliza diversas palavras características dessa profissão. Quaisquer pessoas alheias terão dificuldades para compreender palavras e expressões singulares.

Arrudão (2007) define juridiquês como o "uso de um português arrevesado, palavrório cheio de raciocínio labiríntico e expressões pedantes", ou seja, que expressa além do que deveria, exagerando no uso de termos técnicos.

O formalismo exacerbado impede a compreensão dos jargões jurídicos por grande parte da sociedade. Sendo o léxico jurídico formado por influências do latim e do legado greco-romano, por vezes mostra-se arcaico. O juridiquês é autônomo e de difícil acesso e compreensão pelos leigos no assunto, garantindo o domínio dos operadores sobre o direito.

$\mathrm{O}$ art. $3^{\mathrm{a}}$ da Lei de Introdução às Normas de Direito Brasileiro diz que "Ninguém se escusa de cumprir a lei, alegando que não a conhece", assim como o art. 21 do Código Penal que afirma que "O desconhecimento da lei é inescusável", porém há uma parcela da população, que mesmo tendo o ordenamento jurídico à sua disposição, não possui o acesso completo à ela, por vezes em razão da incompreensão.

Segundo Gnerre (1998, p. 23):

[...] o aspecto específico da linguagem usada nos documentos jurídicos é semelhante ao fenômeno linguístico das linguagens especiais, constituídas em geral de léxicos efetivamente especiais usados nas estruturas gramaticais e sintáticas das variedade linguísticas utilizadas na comunidade. A função central de todas as linguagens especiais é social: elas têm um real valor comunicativo, mas excluem da comunicação as pessoas de comunidades linguísticas externas ao grupo que usa a linguagem especial e, por outro lado, têm a função de reafirmar a identidade dos integrantes do grupo reduzido que tem a linguagem especializada. 
As chamadas "linguagens especiais" são responsáveis pelo distanciamento entre profissionais e leigos, resultando numa espécie ascensão social através do novo código utilizado pelo grupo. O autor também afirma que "a linguagem constitui o arame farpado mais poderoso para bloquear o acesso ao poder" (1998, p. 22), fato que pode ser observado desde a profissionalização do Direito, através do surgimento do processo escrito, já que a escrita era dominada por poucos.

Foucault (1996, p. 37) afirma que "ninguém entrará na ordem do discurso se não satisfizer a certas exigências ou se não for, de início, qualificado para fazê-lo”. Em outras palavras, alguém só poderá fazer uso do discurso- que leva a ideia de apropriação do saber e do poder- se cumprir as regras determinadas pelo grupo, um tipo de hierarquia que exclui maior parte da sociedade.

Sabe-se que a compreensão da linguagem foi fato extremamente importante para a evolução humana, diante dessa afirmação, é totalmente contraditório que a classe Jurídica orgulhe-se de não conseguir uma plena comunicação com seu público. A partir disso, a Associação dos Magistrados do Brasil lançou, em 2004, a Campanha Nacional pela Simplificação da Linguagem Jurídica, após resultados de uma pesquisa que apontava a dificuldade dos brasileiros em entender o "juridiquês". Campanhas como esta têm conscientizado operadores do Direito para que haja uma aproximação da sociedade em geral com a área, já que não é fundamental utilizar-se de uma escrita rebuscada e repleta de termos profissionais para obter certa formalidade.

É de fundamental importância ressaltar que ainda há uma resistência à mudança por parte dos profissionais, seja ela por aspectos sociais ou históricos. A compreensão dos termos em Latim é praticamente impossível pelos leigos dado que não existe o ensino dessa língua nas escolas brasileiras. Essa resistência também pode ser observada porque são poucas as Universidades que oferecem esse ensino em seus cursos, causando a mesma falta de entendimento nos estudantes de Direito, que após formados, buscarão fazer uso dessa linguagem excludente e elitizada.

O uso de uma linguagem acessível ultrapassa o bom senso, vai de encontro ao Princípio da Fraternidade, ou Direito Fraterno, que integra a tríade dos princípios axiológicos supremos, juntamente com Liberdade e Igualdade, ambos reconhecidos como Direitos Fundamentais pela Constituição Federal de 1988, que traz em seu preâmbulo "[...] a igualdade e a justiça como valores supremos de uma sociedade fraterna [...]”, garantindo uma equidade de direitos. 


\section{Conclusões}

Diante dos fatos enunciados, pode-se afirmar que o Princípio do Acesso à Justiça deve ser cumprido e disponível a todos de igual forma, pois trata-se de um direito humano positivado. É perceptível que a principal barreira ao acesso é a linguagem rebuscada e dotada de termos em Latim, mesmo num país onde o idioma oficial é o Português.

A sociedade carece de uma evolução no universo jurídico, onde haja uma atualização de determinados jargões para que o nível de linguagem não seja mais um instrumento de poder, opressão e fator excludente, mas sim uma forma de aproximação e um meio de comunicação completamente acessível.

Portanto, numa era onde o mundo jurídico e o mundo dos fatos estão interligados, cabe aos operadores do direito, utilizar a empatia e o bom senso, adequando sua linguagem e fazendo com que todos possam romper com as barreiras do acesso à justiça.

\section{Referências}

ARRUDÃO, Bias. O juridiquês no banco dos réus. In: Revista Língua Portuguesa, ano I. São Paulo: segmento, n. 2, junho/dez. 2007, p. 18-23.

BRASIL. Código Penal. Decreto-lei no 2.848, de 7 de dezembro de 1940. Rio de Janeiro. 1940.

BRASIL. Lei de Introdução às Normas de Direito Brasileiro. Decreto-lei $n^{o} 4.657$, de 4 de setembro de 1942. Rio de Janeiro. 1942.

BRASIL. Constituição (1988). Constituição da República Federativa do Brasil. Brasília, DF: Senado Federal: Centro Gráfico, 1988

CAPPELLETTI, Mauro; GARTH, Bryant. Acesso à Justiça. Tradução Ellen Gracie Northfleet. Porto Alegre: Fabris, 1988.

ESTADÃO. Três em cada 10 são analfabetos funcionais no Brasil, aponta estudo. Disponível em: <https://epocanegocios.globo.com/Brasil/noticia/2018/08/epoca-negocios-tres-em-cada10-sao-analfabetos-funcionais-no-pais-aponta-estudo.html> Acesso em: 10 jan. 2019.

FOUCAULT, Michel. A Ordem do Discurso. São Paulo: Edições Loyola, 1996.

GNERRE, Maurizio. Linguagem, Escrita e Poder. 4. ed., São Paulo: Martins Fontes, 1998.

HOUAISS, Antônio. Dicionário Houaiss da Língua Portuguesa.

MARANGONI, Pedro. $O$ princípio da fraternidade. Disponível em: $<$ http://cadernojuridico.com.br/artigo/95/O-principio-da-fraternidade $>$ Acesso em 12 jan. 2019. 
MARQUES, Letícia. Do uso da linguagem jurídica e seus aspectos lingüísticos. Disponível em: <https://m.migalhas.com.br/depeso/25796/do-uso-da-linguagem-juridica-e-seus-aspectoslinguisticos $>$ Acesso em 03 jan. 2019.

MENEZES, Ebenezer. Analfabetismo Funcional. Disponível em: <http://www.educabrasil.com.br/analfabetismo-funcional/> Acesso em 10 jan. 2019.

MORAES, Alexandre de. Direitos Humanos Fundamentais. Teoria Geral. Comentários aos arts. $1^{\circ}$ ao $5^{\circ}$ da Constituição da República Federativa do Brasil. Doutrina e Jurisprudência. 2. ed. São Paulo: Atlas S.A., 1998, p. 197.

MOUSINHO, Renata; SCHMID, Evelin; PEREIRA, Juliana; LYRA, Luciana; MENDES, Luciana; NÓBREGA, Vanessa. Aquisição e desenvolvimento da linguagem: dificuldades que podem surgir neste percurso. Revista Psicopedagogia vol. 25 no.78. São Paulo, 2008. Disponível em: $\quad$ http://pepsic.bvsalud.org/scielo.php?script=sci_arttext\&pid=S010384862008000300012> Acesso em: 10 jan. 2019.

STERN, Wilhelm. A linguagem das crianças; Um exame teórico psicológico e linguístico. Disponível

em:

$<$ http://www.institutoelo.org.br/site/files/publications/5157a7235ffccfd9ca905e359020c413.p df> Acesso em: 02 jan. 2019.

VYGOTSKY, Lev Semenovich. Pensamento e Linguagem. Disponível em: $<$ http://www.institutoelo.org.br/site/files/publications/5157a7235ffccfd9ca905e359020c413.p df> Acesso em: 02 jan. 2019. 